\title{
Differences in Pain Location, Intensity and Quality by Pain Pattern in Outpatients with Cancer
}

\author{
Srisuda Ngamkham, PhD, RN, Janean E. Holden, PhD, RN, FAAN, and Diana J. Wilkie, PhD, \\ RN, FAAN \\ Phrapokklao College of Nursing, Chanthaburi, Thailand (Dr. Ngamkham); Division of Acute, \\ Critical, and Long-term Care Programs, School of Nursing, University of Michigan Ann Arbor, \\ Michigan (Dr. Holden); and Department of Biobehavioral Health Science College of Nursing, \\ University of Illinois at Chicago, Chicago, Illinois (Dr. Wilkie)
}

\begin{abstract}
Pain pattern represents how the individual's pain changes temporally with activities or other factors. Understanding pain pattern is important for appropriate timing of pain interventions, but researchers have studied less the temporal aspects of cancer pain than pain location, intensity, and quality parameters. The study purpose was to explore differences in pain location, intensity, and quality by pattern groups in outpatients with cancer. We conducted a comparative, secondary data analysis of data collected from 1994 to 2007.762 outpatients with cancer had completed the 0to-10 Pain Intensity Number Scale and the McGill Pain Questionnaire to measure pain location, quality and pattern. From all possible combinations of the three types of pain patterns, we created seven pain pattern groups. The distribution of pain pattern was: pattern-1 (27\%); pattern-2 (24\%); pattern-3 (8\%); pattern-4 (12\%); pattern-5 (3\%); pattern-6 (18\%); and pattern-7 (8\%). A statistically significant higher proportion of patients with continuous pain patterns (pattern 1, 4, 5, and 7) reported pain location in two or more sites. Patients with pattern 1, 4, and 7 reported statistically significant, higher worst pain mean scores than patients with pattern 2, 3, and 6 (not continuous descriptors). Patients with pattern7 reported statistically significant, higher mean scores (pain rating index-sensory and total number of words selected) than patients with pattern1, $2,3,4$, and 6. Using pain pattern groups may help clinicians to understand temporal changes in cancer pain and to provide more effective pain management by recognizing the high risk if the pain is continuous.
\end{abstract}

\section{Keywords}

Pain; Pattern; Location; Intensity; Quality; Cancer

\section{Introduction}

Pain pattern, the temporal nature of pain and how it changes with time or activity, is a critical variable for appropriate timing of analgesic therapies. Despite its importance, surprisingly little is known about how pain pattern is associated with the other pain characteristics of the pain experience, such as pain location, intensity, and quality. ${ }^{1}$ Previous researchers reported only the frequency of pain pattern descriptor selection within their samples, but few reported the relationship between pain pattern and other pain

Correspondance: Diana J. Wilkie, PhD, RN, FAAN, Department of Biobehavioral Health Science (MC 802) College of Nursing, University of Illinois at Chicago, 845 South Damen Avenue, Room 660 Chicago, IL $60612-7350$ (diwilkie@uic.edu).

None of the authors have a financial interest in Nursing Consult LLC. 
characteristics. ${ }^{2}$ Variability in the temporal pattern of pain poses measurement difficulties ${ }^{3}$ especially when a few patients have more than one pain pattern. ${ }^{4}$ Discovery of relationships among sensory pain characteristics (pain pattern, location, intensity, and quality) would support construct validity of pain pattern measurement and facilitate improved assessment of cancer pain. Furthermore, such knowledge could be useful for health care providers to integrate sensory pain assessment data over time and to better time and choose pain interventions. The purpose of our study was to determine the relationships among pain pattern and other components of sensory pain in patients with cancer who were receiving outpatient care.

\section{Background}

Pain pattern represents how the individual's pain changes with time. ${ }^{5}$ In many pain measurement tools, however, the specific time period for the change is not stipulated typically. Theoretically, pain pattern involves the onset, frequency, duration and changes in pain over time. Additionally, the pain related to activities or other factors may increase or decrease pain intensity or change the location or quality of the pain. ${ }^{6}$ Unfortunately, little systematic knowledge is available about pain pattern in patients with cancer since clinical researchers reported pain pattern in only $1.2 \%$ of the published studies of patients with cancer pain. ${ }^{1}$

Cancer pain remains a major health problem in the United States because the magnitude of the problem, the subjective nature of the pain experience, and the complexity of the disease all make it difficult to control. ${ }^{6,7}$ In total, 1,479,350 new cancer cases and 562,340 deaths from cancer are projected to occur annually in the United States. ${ }^{8}$ Two-thirds of the cancer patients with advanced disease have significant pain. ${ }^{9}$

The etiology of pain in people with cancer may be from many causes, including the cancer itself as it grows and invades or constricts somatic, visceral or neural tissues; $;^{10-13}$ cancer treatments, such as surgery, radiation, and chemotherapy; ${ }^{11}, 14,15$ non-cancerous etiologies; combinations of these causes; or other unknown causes. ${ }^{15}$ The variability in the causes of pain in people with cancer also contributes to difficulty in its control, in part because the sensory characteristics, particularly the location, intensity, quality and pattern of the pain may vary with the etiology of the pain. Unfortunately, we lack sufficient understanding of how pain pattern is related to other sensory pain characteristics (pain location, intensity and quality). Since this area of scientific study is relatively novel, a first step is to determine if these other sensory pain characteristics differ by pain pattern. Therefore, the specific aim of the study was to examine the differences in pain location, intensity, and quality by pain pattern in a large sample of outpatients with cancer.

\section{Conceptual Framework}

Based on concepts consistent with the Gate Control Theory of Pain, ${ }^{16}$ cancer pain has been described as a multidimensional experience that includes sensory, affective, cognitive, and behavioral dimensions. ${ }^{17-20}$ Although many factors can influence an individual's cancer pain experience, not all dimensions may be relevant at the same time or amenable to simultaneous systematic investigation. In this study, we focused on four assessment components of the sensory dimension of cancer pain: its location, intensity, quality, and pattern. 


\section{Method}

\section{Design and Setting}

In a comparative design, we conducted secondary data analysis of four merged databases. The data were collected from patients with cancer in studies conducted with the same study instruments from 1994 to 2007. Three of the studies were conducted at oncology clinics of hospitals in the Puget Sound area of Seattle, Washington. One study was conducted at the oncology clinic at the University of Illinois at Chicago (UIC). All of the primary studies were approved by the UIC Institutional Review Board (IRB), and those conducted in Seattle by the IRBs at the University of Washington and recruitment facilities. We combined the deidentified data from the four studies for this analysis.

\section{Sample}

The inclusion criteria for this study were patients who had been diagnosed with cancer; were 18 years of age or older; were able to read and write English; had completed items about their pain intensity, quality, location, and pattern; and had consented to further research with their data. Seven hundred and sixty-two patients living with cancer met the inclusion criteria.

\section{Procedures}

In the primary studies, the investigators provided for and obtained patients' signatures of informed consent. Then they administered study instruments as baseline measures prior to other study-specific procedures.

\section{Instruments}

Demographic Data Form (DDF)-To provide information about the characteristics of the sample, we obtained the patient's age, gender, race, type of cancer and stage of disease from the DDF. Patient self-report and researcher's thorough review of medical records were the primary sources for the DDF data. ${ }^{15}$

Pain Intensity Number Scale (PINS)—The PINS was used to measure pain intensity, including pain now, pain least, and pain worst. Patients were asked to call their pain a number on a scale of 0 (no pain) to 10 (pain as bad as it could be). The PINS showed high correlation with the Visual Analogue Scale [Kendall's Tau $(\tau)=0.77$ to $0.89 ; p<.001$ ]. ${ }^{21}$

MPQ-We used the 1970 MPQ version ${ }^{18}$ to measure: (1) pain location with a body outline drawing; (2) pain quality with 78 verbal descriptors; and (3) pain pattern with 9 verbal descriptors. The MPQ showed construct validity (sensory, affective, and cognitive) ${ }^{4}, 18,22-28$ and strong criterion-related validity, including concurrent $(\mathrm{r}=0.31-0.40)^{29-31}$ and predictive validity. ${ }^{5,23,30-32}$ Moreover, the MPQ showed strong reliability, including good test-retest reliability (.70-.90) $3,4,20,29-31,33$ and sensitivity to pain type ${ }^{34}$ and treatment effects including radiation therapy, ${ }^{35-37}$ and surgery. ${ }^{38,39}$ The MPQ has been used in at least 30 studies published between 1975 and 2009 of patients with cancer (Ns ranged from 15 to 536) were conducted in a variety of cancer care settings including inpatient, outpatient, hospice, and homes. ${ }^{3,4}, 13,15,18-20,26,29-31,35-53$ The investigators of only one of these 30 studies reported undisclosed usability issues in 6 of 67 participants. ${ }^{41}$ Investigators of another of these 30 studies reported concerns about time to complete the tool ${ }^{4}$ and that an unreported number from 24 subjects expressed difficulty in selecting pain quality descriptors. ${ }^{4}$ The 30 studies were conducted in a variety of cancer care settings including inpatient, outpatient, hospice, and homes. 
PAINReportlt@—This tool is a software program (Nursing Consult LLC., Seattle, WA) that includes an electronic version of the McGill Pain Questionnaire (MPQ-1970 version). ${ }^{18}$ There are no specific reports on the validity and reliability of PAINReportt ${ }^{\circledR}$, but researchers have reported equivalence between the paper-and-pencil version of the MPQ and PAINReporttt. ${ }^{54}$ Demonstrated equivalence extends the validity and reliability from the original form to the computerized version. The PAINReport $\mathrm{A}{ }^{\circledR}$ showed high acceptability to patients. The total mean acceptability score was 11.7 (possible scores ranging from 0-13); $94 \%$ of patients of color reported that it was acceptable, and $78 \%$ of Caucasians did so. Of all patients, $80 \%$ reported mean acceptability scores greater than $10 .{ }^{54}$ Additionally, patients reported that PAINReportt ${ }^{\circledR}$ was a good way to report pain information $(75 \%)$ and easy to use $(94 \%) .55$

Standardized instructions for both the MPQ and PAINReportt ${ }^{\circledR}$ asked patients to:

1. Draw where their pain was located. By counting the pain sites, we created a number of the pain sites variable.

2. Select the word from 78 words that described the nature (quality) of their pain. We used standard scoring procedures ${ }^{18}$ to create the following variables: Pain Rating Index (PRI)-Sensory (S); PRI-Affective (A); PRI-Evaluative (E); PRIMiscellaneous (M); PRI-Total (T); and Number of Words Chosen (NWC).

3. Select the word or words that described how their pain changed with time from three types of pain pattern: (1) continuous, steady, constant; (2) rhythmic, periodic, intermittent; and (3) brief, momentary, transient.

\section{Data Analysis}

We analyzed data using SPSS 15.0 for Windows. We created seven categorical variables to represent all possible combinations of the three pain pattern types. We named these variables as follows: pattern 1 (P1: continuous pain--patient selected continuous, steady, constant or combinations of these three descriptors); pattern 2 (P2: intermittent pain--patient selected rhythmic, periodic, intermittent or combinations of these three descriptors); pattern 3 (P3: transient pain--patient selected brief, momentary, transient or combinations of these three descriptors); pattern 4 (P4: continuous and intermittent pain--patient selected descriptors from both P1 and P2 descriptors); pattern 5 (P5: continuous and transient pain-patient selected descriptors from both $\mathrm{P} 1$ and $\mathrm{P} 3$ descriptors); pattern 6 (P6: intermittent and transient pain--patient selected descriptors from both $\mathrm{P} 2$ and $\mathrm{P} 3$ descriptors): and pattern 7 (P7: continuous, intermittent and transient pain--patient selected descriptors from all P1, P2 and $\mathrm{P} 3$ descriptors). For this study, patients with continuous pain patterns were patients living with pain pattern 1, 4, 5, and 7 that included at least one of continuous words whereas patients without continuous pain pattern were patients living pain pattern 2, 3, and 6 that excluded any of the continuous words.

We described sample characteristics using means and standard deviations for continuous variables and frequencies for categorical variables. We explored differences among pain patterns using a chi square test of homogeneity for the categorical pain location variable and one-way analysis of variance (ANOVA) for the continuous pain intensity and pain quality variables. Differences among the seven pain pattern subgroups were considered statistically significant at two-sided $\mathrm{p}$ values $<0.05$. To follow up the significant chi square test, we compared standardized residuals for each pain pattern to determine which cells differed significantly from expected values. ${ }^{38}$ When one-way ANOVAs were significant, we conducted post-hoc pairwise comparisons using the Games-Howell test, which is considered to be robust when sample sizes and variances are not equal across compared groups. 


\section{Results}

Our final sample included 762 participants with various cancer types and stage of disease (Table 1). The mean age of these cancer patients was $56 \pm 13$ years and most $(80 \%, \mathrm{n}=614)$ participants were Caucasian. Predominant cancers included lung $(30 \%, \mathrm{n}=230)$, head and neck $(22 \%, \mathrm{n}=165)$, breast $(15 \%, \mathrm{n}=112)$, and prostate $(13 \%, \mathrm{n}=96)$, and almost half of the sample had stage IV disease $(48 \%, \mathrm{n}=368)$.

\section{Pain characteristics of the sample}

Overall, $48 \%$ of patients with cancer reported pain location in less than two sites, and 52\% reported two or more pain sites. The frequency distribution of the pain pattern groups are shown in Figure 1.

\section{Difference in number of pain sites by pain pattern groups}

The frequency distribution of the number of pain sites by pain pattern is illustrated in Table 2. Overall, a higher proportion of patients (32\%) with continuous pain patterns (P1, P4, P5, and P7) reported pain located in two or more sites, and a higher proportion of patients (29\%) without continuous pain pattern (P2, P3, P6) reported pain located in less than two pain sites. The overall difference was statistically significant by pain pattern groups.

\section{Difference in pain intensity scores by pain pattern groups}

Figure 2 and Table 3 show the average pain-intensity scores by the seven pain patterns. Patients with P7 reported higher mean scores for pain now (4.2 \pm 2.7$)$, and worst pain $(6.9 \pm$ 2.3) than did patients with other pain patterns. For least pain, patients with P5 reported higher pain score least pain $(2.9 \pm 2.0)$ than patients with P7. These differences were statistically significant by pain pattern group for least pain, pain now, and worst pain. Posthoc pairwise comparisons indicated that patients with continuous pain pattern groups ( $\mathrm{P} 1$, P4, P5, and P7) had significantly higher mean scores for least pain, pain now, and worst pain than patients with intermittent pain pattern groups (P2, P3, and P6).

\section{Difference in pain quality scores by pain pattern groups}

The differences in pain quality scores by pain pattern group appear in Figure 3 and Table 4 . Patients with P7 reported the highest mean pain quality scores: PRI-S (17.5 \pm 7.8$)$; PRI-A (5.2 \pm 4.8); PRI-E ( $2.9 \pm 1.7)$; PRI-M (6.0 \pm 4.0$)$; PRI-T ( $31.5 \pm 16.3)$; and NWC (11.6 \pm 4.8), whereas patients with P3 reported the lowest mean scores of pain quality: PRI-S (7.0 \pm 6.1); PRI-A ( $2.7 \pm 2.1)$; PRI-E (1.1 \pm 1.4$)$; PRI-M (1.5 \pm 2.6$)$; PRI-T (12.3 \pm 10.6$)$; and NWC $(5.4 \pm 3.6)$. There was a statistically significant difference in pain quality scores by pain pattern group: PRI-S $\left[\mathrm{F}_{(6,755)}=17.0, p<.05\right]$; PRI-A $\left[\mathrm{F}_{(6,755)}=8.9, p<.05\right]$; PRI-E $\left[\mathrm{F}_{(6,755)}=10.6, p<.05\right] ;$ PRI-M $\left[\mathrm{F}_{(6,755)}=18.0, p<.05\right]$; PRI-T $\left[\mathrm{F}_{(6,755)}=19.7, p<.05\right]$; and NWC $\left[\mathrm{F}_{(6,755)}=19.0, p<.05\right]$. Post-hoc pairwise comparisons indicated that patients with continuous pain pattern groups (P1, P4, P5, and P7) had significantly higher mean scores for PRIS, PRIA, PRIE, PRIM, PRIT, and NWC than patients with intermittent pain pattern groups (P2, $\mathrm{P} 3$, and $\mathrm{P} 6)$.

\section{Discussion}

Our findings are indicative of the complex variability in the temporal character of pain experienced by people living with cancer. In this large sample, about one-fourth reported continuous pain only; about one-fourth reported only intermittent pattern; and less than onetenth reported only transient pattern. About one-fifth of the sample reported a combination of intermittent and transient pain patterns, and the rest reported other combinations of pain patterns. There were, however, distinct differences in pain location, intensity, and quality by 
pain pattern groups. Patients with continuous pain pattern groups reported two or more pain locations and higher pain intensity and pain quality scores. Further interpretation and conclusions about our novel findings would be speculative without additional investigation of the explanatory power of personal, oncologic, and analgesic variables that we did not consider in this initial study to determine if pain location, intensity and quality differed by pain pattern. Our findings provide strong evidence to support additional research focused on these other variables, but a larger sample is needed to increase the number of patients in all pain pattern groups. In our sample, P5 and P7 and especially P3 had small numbers of subjects, which limits conclusions that can be drawn about those patterns, particularly in relation to exploration of other personal, oncologic or analgesic variables. This issue is especially important since P5 had only 24 subjects. Other researchers' findings, however, provide additional insights to guide design of future studies to refine knowledge of pain pattern in people with cancer.

\section{Pain Location}

Based on anatomical distributions of the pain, when patients reported pain in multiple locations, it could be interpreted as evidence of disease progression or metastases. ${ }^{56} \mathrm{We}$ found that the proportion of patients (29\%) without continuous pain as part of the pain pattern (i.e., P2, P3, and P6) reported mostly one pain site, whereas the proportion of patients (32\%) with continuous pain as part of the pain pattern (i.e., P1, P4, P5, and P7) frequently reported two or more pain sites. It seems possible that patients with continuous pain pattern may have had more advanced cancer than patients without continuous pain pattern--a hypothesis that could be explored in future research.

Pain in people with cancer results from many causes. One cause is somatic tissue damage, which was reported as pain that was well-localized compared to patients with diffuse pain distribution that resulted from visceral tissue damage. ${ }^{57}$ Samuelsson and Hedner ${ }^{58}$ found that both intermittent and continuous pain patterns were related to neuropathic pain, whereas intermittent pain patterns were related to somatic and visceral pain. From previous studies, it is known that patients with cancer generally reported more than two pain sites. ${ }^{15,31,45,50}$ Based on previous research, it is plausible that many of our patients were likely to have some neuropathic pain. Further research is needed to study the relationships between pain pattern groups and type of cancer pain, which may also relate to the type of cancer or its metastatic distribution.

Patients' movement is a factor that aggravates their pain. ${ }^{51}$ Cancer located in the weightbearing boney structures may produce more pain when patients move than metastases to non weight-bearing bones. ${ }^{59}$ Therefore, cancer location may be directly related to pain location. Our results indicated that patients with continuous pain pattern reported multiple pain sites more frequently than those without continuous pain pattern. That finding may indicate that patients with continuous pain pattern may have tumor-related pain rather than treatmentrelated pain. However, such an interpretation should be confirmed by medical record data, such as physical or diagnostic examinations, which were not available in the de-identified database.

\section{Pain Intensity}

Patients with pain pattern groups that included continuous pain reported more intense pain (least pain, pain now, and worst pain) than patients without a continuous component to their pain pattern. Our results showed not only a statistically significant finding, which may be an artifact of the large sample, but also a clinically significant difference between patients with and without continuous pain patterns. ${ }^{60}$ Burrows and colleagues ${ }^{47}$ reported that patients with cancer who had pain from somatic causes reported higher mean scores for least pain, 
pain now, and worst pain than patients with visceral and neuropathic pain. Yet, Wilkie and colleagues ${ }^{15}$ found that patients with neuropathic/nociceptive pain (mixed pain) reported more intense pain than patients with only nociceptive pain or neuropathic pain. Nociceptive pain results from somatic (skin, muscle, bone) or visceral tissue damage whereas neuropathic pain results from neural tissue damage or alteration in pain processing. ${ }^{15}$ Perhaps patients in our study with pain patterns that included continuous pain also had mixed pain, a hypothesis we did not test. However, Wincent and colleagues ${ }^{57}$ found that both continuous and non-continuous pain patterns may be caused by the same types of tissue damage (somatic, visceral, and neural tissue), but the pain patterns may differ in clinical characteristics, such as neurological signs, when pain involves neural tissues. ${ }^{57}$ The inconclusive findings from the previous research are indicative of the need for additional research with well-characterized etiology of the pain as well as its sensory characteristics.

\section{Pain Quality}

Overall, patients with pain pattern groups inclusive of continuous pain reported higher mean scores for pain quality than patients without continuous pain. Continuous pain may have had a greater impact on patients' physical, emotional, and cognitive status than non-continuous pain. Sist and colleagues ${ }^{42}$ indicated that depressed patients had higher affective pain scores and selected more affective descriptors than non-depression patients. Also, Wilkie and Keefe ${ }^{31}$ reported that pain quality showed moderately strong correlation with diverting attention, praying and hoping, catastrophizing, and increasing activity. Patients with cancer who engaged in catastrophizing reported much lower levels of hope than patients not engaging in catastrophizing. ${ }^{61}$ Stevens, Dibble and Miaskowski ${ }^{51}$ found that emotion and fatigue were aggravating factors that were associated with all pain parameters. It seems that patients with pain patterns inclusive of continuous pain may have had more complex physical and psychological pain quality components than patients without continuous pain. Furthermore, patients with P7 had pain quality scores almost double the average mean score for the entire sample. This result might mean that patients with P7 were likely to be suffering more than those with other pain patterns and therefore needed to have their pain relieved quickly. However, this possibility must be confirmed with other psychosocial data.

Our findings provide strong evidence that cancer pain has complex variability in its temporal character, supporting the conclusions of Graham et al. ${ }^{3}$ and McGuire. ${ }^{4}$ However, despite our large sample size in this study, for some patterns there were still too few patients to compare with other pain characteristics. Thus, we need a larger sample size to analyze pain pattern groups, especially the rare groups, as they relate to other variables.

\section{Study Limitations}

The group of patients studied was heterogeneous in terms of the types of cancer and stages of cancer. Additionally, the sample was mainly Caucasian, which limits the generalizability of the findings. Since the data were merged from one study conducted in Chicago and three studies conducted in Seattle, our study findings are generalizable to people receiving care at the 12 involved institutions. Another limitation is the long time period over which we collected the data. Cancer treatments may have changed over the 14 years, which may impact patients' pain and it is unknown how those changes may have influenced the relationships among pain patterns, location, intensity, and quality. We did not analyze how cancer or pain treatments were related to pain pattern, which limits interpretation of findings relative to these variables. Further research is needed to consider how each pain variable is associated with pain patterns, what pain descriptors are related to pain patterns, how pain patterns change over time, especially with various cancer treatment or after pain treatment, and the influence of patient and disease characteristics on pain patterns. 


\section{Nursing Implications}

From our results, nurses or clinicians who are taking care of patients with cancer should recognize that pain patterns are likely to be associated with differences in pain location, intensity, and quality. Results from our study indicate that patients with a continuous component to their pain pattern are at most risk for also having pain in multiple sites that is more intense and of a complex nature and often associated with psychosocial issues. Other factors (e.g., personal, oncologic, analgesic) not analyzed in our study, however, may have greater power than pain patterns to explain the differences we found in the sensory pain characteristics. Using pain pattern information in clinical practice may help nurses or clinicians to better understand pain so that they provide more effective pain management strategies. For instance, patients with continuous pain patterns are at risk for more severe/ complex pain and should receive around-the-clock analgesics. Similarly patients without continuous pain patterns are likely to have less severe/complex pain and should receive as needed analgesic drugs (PRN), especially if they are also experiencing side effects from the analgesics. Finally, nurses or clinicians should encourage patients to take short acting analgesics before they engage in activities that are associated with brief or transient pain patterns.

Another important but indirect implication of this study is that patients with cancer can use the MPQ to describe the multiple dimensions of the cancer pain experience. There is a common assumption that the MPQ is too long to be used in clinical practice, especially oncology practice. In fact the senior author of the study reported in this article had such an opinion when she began her research career 20 years ago. She quickly discovered that her clinical impression was incorrect because patients with cancer lacked the language to describe their abstract but complex experience of pain. They, however, were easily able to use the MPQ to make their pain concrete and describe their pain experience to others. Depending on the complexity of their pain and their mental status, the first time they are asked to complete the MPQ, they require about 10-15 minutes to complete the long form, the version with sufficient data to guide therapies specific for the nociceptive or neuropathic components of their pain and the psychosocial issues that they also relate to their pain. No other pain assessment tool provides these data in one tool. This fact is important because in 1953 Ronald Melzack began to capture the MPQ descriptors from patients with pain and then systematically developed the tool, publishing it first in 1975. Since 1975, it has stood the test of time as a valid and reliable measure, but it could be strengthened with additional systematic research such as discovered in our study. Clearly research is needed to understand barriers to adopting the MPQ in clinical practice.

Today, if time is an issue, the patients can complete the MPQ while they are waiting to be seen by their providers. A disadvantage of the MPQ paper version, though, is the need to enter the data into a clinical database or the electronic medical record (EHR). Fortunately, PAINReportt, ${ }^{\circledR}$ the computerized MPQ version, overcomes this documentation issue by allowing the patient to complete it in the waiting room on a touch screen computer that is linked to the EHR and a summary report can be opened by the clinician at the point of care. ${ }^{54,55}$ Such clinical use allows the patient, the expert about how the pain feels, to complete the pain assessment tool and also allows the clinician to spend precious clinical time not to collect the data but rather to interpret the data, ask for clarifications or validation while seeing the patient and then to make clinical decisions about managing the pain more effectively. If the setting does not have computer access at the point of care, the patient can print the summary report and hand-deliver it to the clinician during the clinical visit. Another advantage of this approach is that the setting can conduct its own studies of pain and discover what factors facilitate improved pain outcomes. 


\section{Conclusions}

In a relatively large sample, cancer pain presented with complex variability in its temporal character. Pain location, intensity, and quality had distinct differences by the various pain pattern groups. Patients with continuous pain patterns reported two or more pain locations and higher pain intensity and pain quality scores than patients without a continuous component to their pain pattern. Further research with larger samples or samples stratified by pain pattern is needed to study how other personal, oncologic and analgesic variables are related to pain pattern.

\section{Acknowledgments}

This research was made possible by Grant Numbers R29 CA62477, 2R01 CA62477, 1R01 CA81918, and 2 R01 CA081918 from the National Institutes of Health, National Cancer Institute and Grant Number RPG-96-001-03PBP from the National Office of the American Cancer Society, and publication was supported by Grant Number P30 NR010680 from the National Institute Nursing Research, all awarded to Diana J. Wilkie. Its contents are solely the responsibility of the authors and do not necessarily represent the official views of the National Cancer Institute or the American Cancer Society. The final peer-reviewed manuscript is subject to the National Institutes of Health Public Access Policy. PAINReportIt ${ }^{\circledR}$ is commercially available from Nursing Consult LLC (801-4140627).

\section{References}

1. Jensen MP. The validity and reliability of pain measures in adults with cancer. J Pain. 2003; 4(1):221. [PubMed: 14622723]

2. Ngamkham, S.; Catherine, V.; Finnegan, L.; Holden, J.; Wang, ZJ.; Wilkie, D. The McGill Pain Questionnaire as a multidimensional measure in cancer populations. In review

3. Graham C, Bond SS, Gerkovich MM, Cook MR. Use of the McGill Pain Questionnaire in the assessment of cancer pain: replicability and consistency. Pain. 1980; 8(3):377-387. [PubMed: 7402695]

4. McGuire DB. Assessment of pain in cancer inpatients using the McGill Pain Questionnaire. Oncol Nurs Forum. 1984; 11(6):32-37. [PubMed: 6568710]

5. Dubuisson D, Melzack R. Classification of clinical pain descriptions by multiple group discriminant analysis. Experimental Neurology. 1976; 51(2):480-487. [PubMed: 1269574]

6. Wilkie, DJ.; Monreal, DW. Pain Management. Appleton \& Lange; Stamford, CT: 1999.

7. McGuire, DB. The Multiple Dimensions of Cancer Pain. Jones and Bartlett; Boston, MA: 1995.

8. Jemal A, Siegel R, Ward E, Hao Y, Xu J, Thun MJ. Cancer statistics, 2009. CA Cancer J Clin. 2009; 59(4):225-249. [PubMed: 19474385]

9. Regan JM, Peng P. Neurophysiology of cancer pain. Cancer Control. 2000; 7(2):111-119. [PubMed: 10783815]

10. Banning A, Sjogren P, Henriksen H. Pain causes in 200 patients referred to a multidisciplinary cancer pain clinic. Pain. 1991; 45(1):45-48. [PubMed: 1861877]

11. Caraceni A, Portenoy RK. An international survey of cancer pain characteristics and syndromes. IASP Task Force on Cancer Pain. International Association for the Study of Pain. Pain. 1999; 82(3):263-274. [PubMed: 10488677]

12. Mercadante S, Armata M, Salvaggio L. Pain characteristics of advanced lung cancer patients referred to a palliative care service. Pain. 1994; 59(1):141-145. [PubMed: 7531837]

13. Twycross RG, Fairfield S. Pain in far-advanced cancer. Pain. 1982; 14(3):303-310. [PubMed: 6218464]

14. Grond S, Zech D, Diefenbach C, Radbruch L, Lehmann KA. Assessment of cancer pain: a prospective evaluation in 2266 cancer patients referred to a pain service. Pain. 1996; 64(1):107114. [PubMed: 8867252]

15. Wilkie DJ, Huang HY, Reilly N, Cain KC. Nociceptive and neuropathic pain in patients with lung cancer: A comparison of pain quality descriptors. J Pain Symptom Manage. 2001; 22(5):899-910. [PubMed: 11728793] 
16. Melzack R, Wall PD. Pain mechanisms: A new theory. Science. 1965; 150(699):971-979. [PubMed: 5320816]

17. McGuire, DB. Measuring pain. In: Frank-Stromborg, M.; Olsen, S., editors. Instruments for clinical health care research. Jones and Bartlett; Boston, MA: 1997. p. 528-564.

18. Melzack R. The McGill Pain Questionnaire: Major properties and scoring methods. Pain. 1975; 1(3):277-299. [PubMed: 1235985]

19. Ahles TA, Blanchard EB, Ruckdeschel JC. The multidimensional nature of cancer-related pain. Pain. 1983; 17(3):277-288. [PubMed: 6657288]

20. Wilkie DJ, Keefe FJ, Dodd MJ, Copp LA. Behavior of patients with lung cancer: description and associations with oncologic and pain variables. Pain. 1992; 51(2):231-240. [PubMed: 1484719]

21. Wilkie DJ, Lovejoy N, Dodd M, Tesler M. Cancer pain intensity measurement: concurrent validity of three tools--finger dynamometer, pain intensity number scale, visual analogue scale. Hosp J. 1990; 6(1):1-13. [PubMed: 2379920]

22. Prieto EJ, Hopson L, Bradley LA, et al. The language of low back pain: factor structure of the McGill pain questionnaire. Pain. 1980; 8(1):11-19. [PubMed: 6445051]

23. Boureau F, Doubrere JF, Luu M. Study of verbal description in neuropathic pain. Pain. 1990; 42(2):145-152. [PubMed: 2247313]

24. Byrne M, Troy A, Bradley LA, et al. Cross-validation of the factor structure of the McGill Pain Questionnaire. Pain. 1982; 13(2):193-201. [PubMed: 6214754]

25. Kremer EF, Atkinson JH Jr. Pain measurement: construct validity of the affective dimension of the McGill Pain Questionnaire with chronic benign pain patients. Pain. 1981; 11(1):93-100. [PubMed: 7301404]

26. Kremer EF, Atkinson JH Jr. Ignelzi RJ. Pain measurement: The affective dimensional measure of the McGill Pain Questionnaire with a cancer pain population. Pain. 1982; 12(2):153-163. [PubMed: 7070825]

27. Reading AE, Hand DJ, Sledmere CM. A comparison of response profiles obtained on the McGill Pain Questionnaire and an adjective checklist. Pain. 1983; 16(4):375-383. [PubMed: 6622047]

28. Turk DC, Rudy TE, Salovey P. The McGill Pain Questionnaire reconsidered: confirming the factor structure and examining appropriate uses. Pain. 1985; 21(4):385-397. [PubMed: 4000688]

29. Wilkie DJ, Williams AR, Grevstad P, Mekwa J. Coaching persons with lung cancer to report sensory pain. Literature review and pilot study findings. Cancer Nurs. 1995; 18(1):7-15. [PubMed: 7866980]

30. Berry DL, Wilkie DJ, Huang HY, Blumenstein BA. Cancer pain and common pain: A comparison of patient-reported intensities. Oncol Nurs Forum. 1999; 26(4):721-726. [PubMed: 10337650]

31. Wilkie DJ, Keefe FJ. Coping strategies of patients with lung cancer-related pain. Clin J Pain. 1991; 7:292-299. [PubMed: 1809442]

32. Wagstaff S, Smith OV, Wood PH. Verbal pain descriptors used by patients with arthritis. Ann Rheum Dis. 1985; 44(4):262-265. [PubMed: 3985692]

33. Melzack R. Prolonged relief of pain by brief, intense transcutaneous somatic stimulation. Pain. 1975; 1(4):357-373. [PubMed: 141644]

34. Klepac RK, Dowling J, Hauge G. Sensitivity of the McGill Pain Questionnaire to intensity and quality of laboratory pain. Pain. 1981; 10(2):199-207. [PubMed: 7267136]

35. Epstein JB, Wilkie DJ, Fischer DJ, Kim YO, Villines D. Neuropathic and nociceptive pain in head and neck cancer patients receiving radiation therapy. Head Neck Oncol. 2009; 1(1):26. [PubMed: 19594943]

36. Huang HY, Wilkie DJ, Chapman CR, Ting LL. Pain trajectory of Taiwanese with nasopharyngeal carcinoma over the course of radiation therapy. J Pain Symptom Manage. 2003; 25(3):247-255. [PubMed: 12614959]

37. Epstein JB, Stewart KH. Radiation therapy and pain in patients with head and neck cancer. Eur $\mathbf{J}$ Cancer. 1993; 29B(3):191-199.

38. Macdonald L, Bruce J, Scott NW, Smith WC, Chambers WA. Long-term follow-up of breast cancer survivors with post-mastectomy pain syndrome. Br J Cancer. 2005; 92(2):225-230. [PubMed: 15655557] 
39. Peintinger F, Reitsamer R, Stranzl H, Ralph G. Comparison of quality of life and arm complaints after axillary lymph node dissection vs sentinel lymph node biopsy in breast cancer patients. $\mathrm{Br} \mathrm{J}$ Cancer. 2003; 89(4):648-652. [PubMed: 12915872]

40. Zimmerman L, Pozehl B, Duncan K, Schmitz R. Effects of music in patients who had chronic cancer pain. West J Nurs Res. 1989; 11(3):298-309. [PubMed: 2750142]

41. Talmi YP, Waller A, Bercovici M, et al. Pain experienced by patients with terminal head and neck carcinoma. Cancer. 1997; 80(6):1117-1123. [PubMed: 9305713]

42. Sist TC, Florio GA, Miner MF, Lema MJ, Zevon MA. The relationship between depression and pain language in cancer and chronic non-cancer pain patients. J Pain Symptom Manage. 1998; 15(6):350-358. [PubMed: 9670635]

43. Greenwald HP. Interethnic differences in pain perception. Pain. 1991; 44(2):157-163. [PubMed: 2052381]

44. Dobratz MC. Word choices of advanced cancer patients: frequency of nociceptive and neuropathic pain. Am J Hosp Palliat Care. 2008; 25(6):469-475. [PubMed: 18843139]

45. Coward DD, Wilkie DJ. Metastatic bone pain. Meanings associated with self-report and selfmanagement decision making. Cancer Nurs. 2000; 23(2):101-108. [PubMed: 10763280]

46. Beck SL. The therapeutic use of music for cancer-related pain. Oncol Nurs Forum. 1991; 18(8): 1327-1337. [PubMed: 1762973]

47. Burrows M, Dibble SL, Miaskowski C. Differences in outcomes among patients experiencing different types of cancer-related pain. Oncol Nurs Forum. 1998; 25(4):735-741. [PubMed: 9599356]

48. Dobratz MC. Patterns of advanced cancer pain in home hospice patients. Cancer Nursing. 2001; 24(4):294-299. [PubMed: 11502038]

49. Heim HM, Oei TP. Comparison of prostate cancer patients with and without pain. Pain. 1993; 53(2):159-162. [PubMed: 8336985]

50. Nicholson BA, McGuire DB, Maurer VE. Assessment of pain in head and neck cancer patients using the McGill Pain Questionnaire. ORL Head Neck Nurs. 1988; 6:8-12.

51. Stevens PE, Dibble SL, Miaskowski C. Prevalence, characteristics, and impact of postmastectomy pain syndrome: An investigation of women's experiences. Pain. 1995; 61(1):61-68. [PubMed: 7644250]

52. Zimmerman L, Story KT, Gaston-Johansson F, Rowles JR. Psychological variables and cancer pain. Cancer Nurs. 1996; 19(1):44-53. [PubMed: 8904386]

53. Fischer DJ, Villines D, Kim YO, Epstein JB, Wilkie DJ. Anxiety, depression, and pain: Differences by primary cancer. Support Care Cancer. 2009; 18(7):801-810. [PubMed: 19685346]

54. Wilkie DJ, Judge MK, Berry DL, Dell J, Zong S, Gilespie R. Usability of a computerized PAINReportIt in the general public with pain and people with cancer pain. J Pain Symptom Manage. 2003; 25(3):213-224. [PubMed: 12614956]

55. Huang HY, Wilkie DJ, Zong SP, et al. Developing a computerized data collection and decision support system for cancer pain management. Comput Inform Nurs. 2003; 21(4):206-217. [PubMed: 12869874]

56. Caraceni A, Weinstein SM. Classification of cancer pain syndromes. Oncology (Williston Park). 2001; 15(12):1627-1640. 1642. discussion 1642-1623, 1646-1627. [PubMed: 11780704]

57. Wincent A, Liden Y, Arner S. Pain questionnaires in the analysis of long lasting (chronic) pain conditions. Eur J Pain. 2003; 7(4):311-321. [PubMed: 12821401]

58. Samuelsson H, Hedner T. Pain characterization in cancer patients and the analgetic response to epidural morphine. Pain. 1991; 46(1):3-8. [PubMed: 1716752]

59. Ahles TA, Martin JB. Cancer pain: A multidimensional perspective. Hosp J. 1992; 8(1-2):25-48. [PubMed: 1286851]

60. Hanley MA, Jensen MP, Ehde DM, et al. Clinically significant change in pain intensity ratings in persons with spinal cord injury or amputation. Clin J Pain. 2006; 22(1):25-31. [PubMed: 16340590]

61. Lai YH, Chang JT, Keefe FJ, et al. Symptom distress, catastrophic thinking, and hope in nasopharyngeal carcinoma patients. Cancer Nurs. 2003; 26(6):485-493. [PubMed: 15022980] 


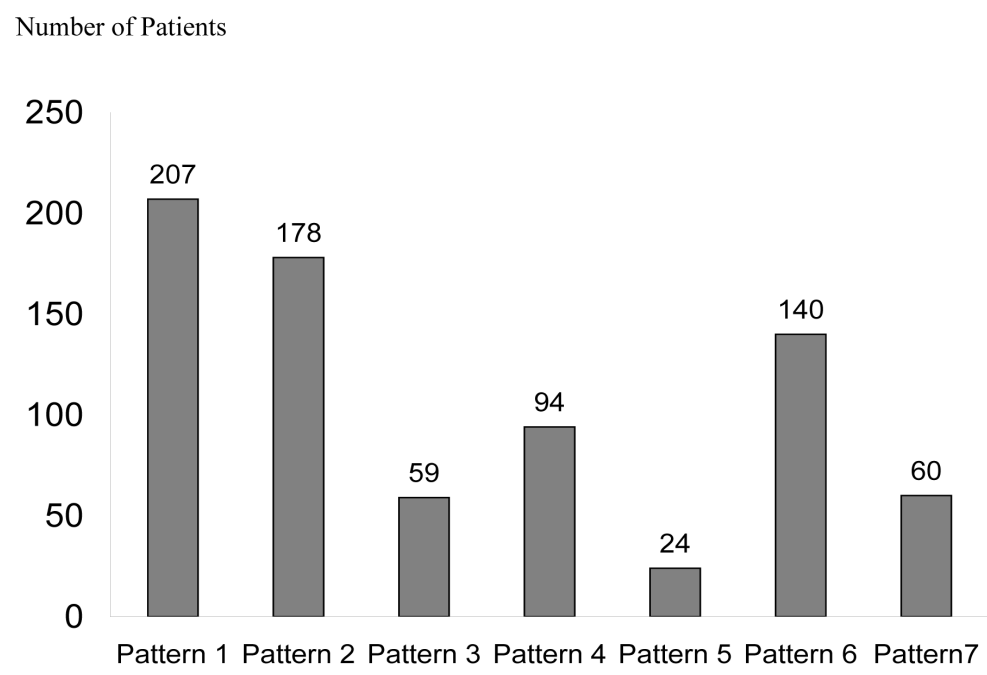

Pattern 1 Continuous only; Pattern 2 Intermittent only; Pattern 3 Transient only; Pattern 4 Continuous and

Intermittent; Pattern 5 Continuous and Transient; Pattern 6 Intermittent and Transient; Pattern 7

Continuous, Intermittent, and Transient

Figure 1.

Frequency of Patients by Pain Pattern 


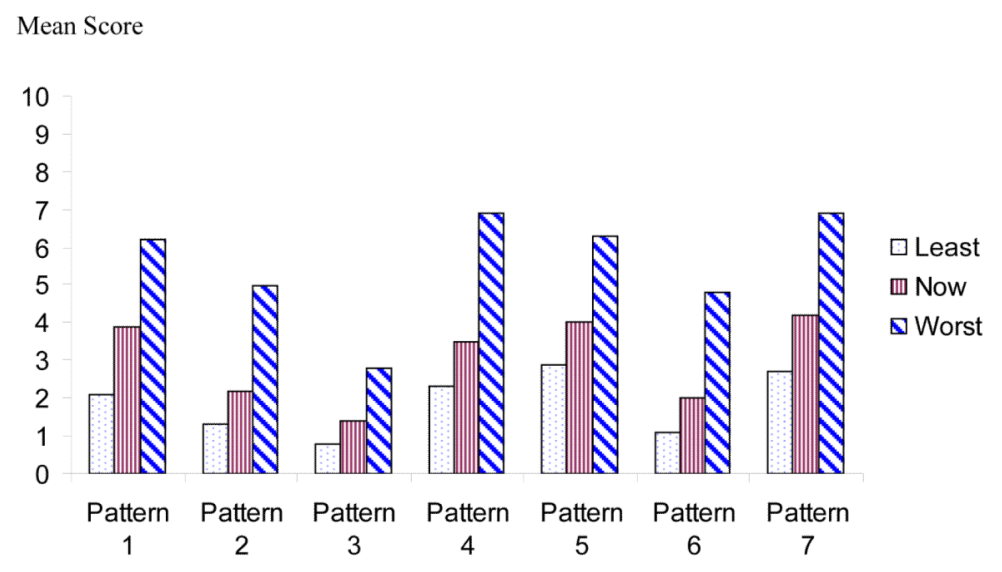

Figure 2.

Mean Pain Intensity Scores by Pain Pattern Groups 


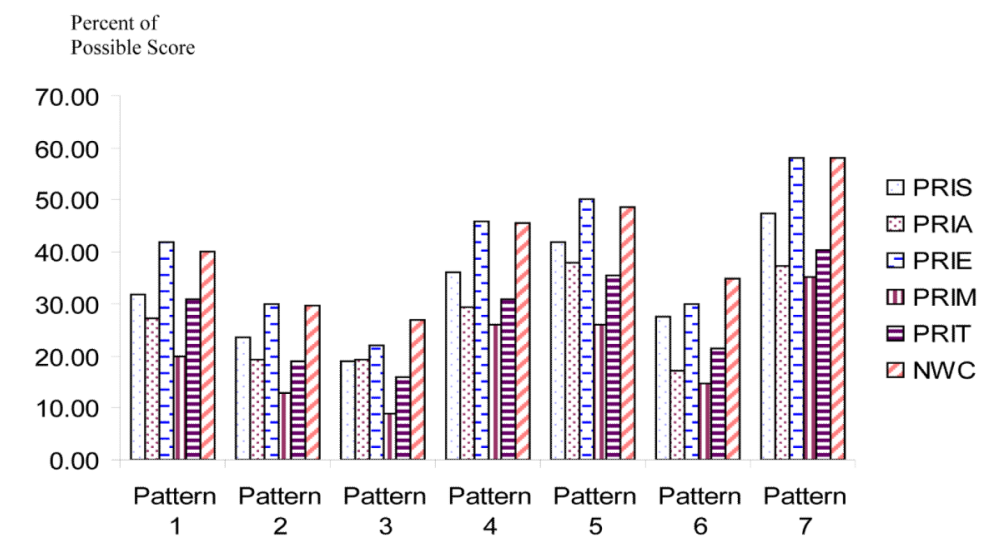

PRI-S = Pain Rating Index-Sensory; PRI-A = Pain Rating Index-Affective; PRI-E = Pain Rating Index-Evaluation; PRI-M = Pain Rating Index-Miscellaneous; PRI-T = Pain Rating Index-Total; NWC = Number of Words Chosen

Figure 3.

Percent of Possible Pain Quality Scores by Pain Pattern 
Table 1

Demographic, Cancer and Pain Characteristics of the Sample $(\mathrm{N}=762)$

\begin{tabular}{|c|c|c|}
\hline Characteristics & $\mathbf{N}$ & $(\%)$ \\
\hline \multicolumn{3}{|c|}{$\begin{array}{l}\text { Age in Years }(\text { Minimum }=18, \text { Maximum }=84) \\
\text { Mean } \pm S D=56.3 \pm 12.7 \\
\text { Gender }\end{array}$} \\
\hline Male & 458 & 60.1 \\
\hline Female & 304 & 39.9 \\
\hline \multicolumn{3}{|l|}{ Race/Ethnicity } \\
\hline Caucasian & 614 & 80.6 \\
\hline Non Caucasian & 148 & 19.4 \\
\hline African American & 84 & 11.0 \\
\hline Hispanic/Latino & 18 & 2.4 \\
\hline Asian American & 24 & 3.1 \\
\hline Native American & 6 & 0.8 \\
\hline Pacific Islanders & 16 & 2.1 \\
\hline \multicolumn{3}{|l|}{ Type of Cancer } \\
\hline Lung & 230 & 30.2 \\
\hline Head \& Neck & 165 & 21.7 \\
\hline Breast & 112 & 14.7 \\
\hline Prostate & 96 & 12.6 \\
\hline Cervical & 20 & 2.6 \\
\hline Colorectal & 20 & 2.6 \\
\hline Sarcoma & 31 & 4.1 \\
\hline Myeloma, Lymphoma, Leukemia & 19 & 2.4 \\
\hline Other Cancers & 69 & 9.1 \\
\hline \multicolumn{3}{|l|}{ Stage of Cancer } \\
\hline Stage I & 88 & 11.5 \\
\hline Stage II & 126 & 16.5 \\
\hline Stage III & 180 & 23.6 \\
\hline Stage IV & 368 & 48.3 \\
\hline
\end{tabular}


Table 2

Pain Location by Pain Pattern Groups (N = 762)

\begin{tabular}{|c|c|c|c|c|c|c|c|}
\hline $\begin{array}{l}\text { Number of } \\
\text { pain sites } \\
\text { (Mean = 2, } \\
\text { SD = 2.0; } \\
\text { Minimum - }\end{array}$ & $\begin{array}{c}\text { Pattern } 1 \\
\text { Continuous } \\
\text { only }\end{array}$ & $\begin{array}{c}\text { Pattern } 2 \\
\text { Intermittent } \\
\text { only }\end{array}$ & $\begin{array}{l}\text { Pattern } 3 \\
\text { Transient } \\
\text { only }\end{array}$ & $\begin{array}{c}\text { Pattern } 4 \\
\text { Continuous } \\
\text { and } \\
\text { Intermittent }\end{array}$ & $\begin{array}{c}\text { Pattern } 5 \\
\text { Continuous } \\
\text { and } \\
\text { Transient }\end{array}$ & $\begin{array}{c}\text { Pattern 6 } \\
\text { Intermittent } \\
\text { and } \\
\text { Transient }\end{array}$ & $\begin{array}{c}\text { Pattern } 7 \\
\text { Continuous, } \\
\text { Intermittent, } \\
\text { and } \\
\text { Transient }\end{array}$ \\
\hline $\begin{array}{l}\text { Maximum } \\
=0-15)\end{array}$ & $\underset{(\%)}{N}$ & $\begin{array}{l}\mathbf{N} \\
(\%)\end{array}$ & $\begin{array}{c}\mathbf{N} \\
(\%)\end{array}$ & $\underset{(\%)}{N}$ & $\begin{array}{l}\mathbf{N} \\
(\%)\end{array}$ & $\underset{(\%)}{N}$ & $\underset{(\%)}{N}$ \\
\hline$\leq 1$ site & $\begin{array}{c}98 \\
(12.9)\end{array}$ & $\begin{array}{c}108 \\
(14.2)\end{array}$ & $\begin{array}{c}46 \\
(6.0)\end{array}$ & $\begin{array}{c}27 \\
(3.5)\end{array}$ & $\begin{array}{c}7 \\
(0.9)\end{array}$ & $\begin{array}{c}67 \\
(8.8)\end{array}$ & $\begin{array}{c}10 \\
(1.3)\end{array}$ \\
\hline$\geq 2$ sites & $\begin{array}{c}109 \\
(14.3)\end{array}$ & $\begin{array}{c}70 \\
(9.2)\end{array}$ & $\begin{array}{c}13 \\
(1.7)\end{array}$ & $\begin{array}{c}67 \\
(8.8)\end{array}$ & $\begin{array}{c}17 \\
(2.2)\end{array}$ & $\begin{array}{c}73 \\
(9.6)\end{array}$ & $\begin{array}{c}50 \\
(6.6)\end{array}$ \\
\hline
\end{tabular}

Overall $\chi^{2}(6)=73.7, p<0.05$ 
Table 3

Pain Intensity by Pain Pattern Groups $(\mathrm{N}=762)$

\begin{tabular}{|c|c|c|c|c|c|c|c|c|c|}
\hline $\begin{array}{c}\text { Type of } \\
\text { Pain } \\
\text { Intensity } a\end{array}$ & Total & $\begin{array}{c}\text { Pattern } 1 \\
\text { Continuous } \\
\text { only }\end{array}$ & $\begin{array}{c}\text { Pattern 2 } \\
\text { Intermitte } \\
\text { nt } \\
\text { only }\end{array}$ & $\begin{array}{c}\text { Pattern } 3 \\
\text { Transient } \\
\text { only }\end{array}$ & $\begin{array}{c}\text { Pattern } 4 \\
\text { Continuous } \\
\text { and } \\
\text { Intermittent }\end{array}$ & $\begin{array}{c}\text { Pattern 5 } \\
\text { Continuous } \\
\text { and } \\
\text { Transient }\end{array}$ & $\begin{array}{c}\text { Pattern } 6 \\
\text { Intermittent } \\
\text { and } \\
\text { Transient }\end{array}$ & $\begin{array}{c}\text { Pattern } 7 \\
\text { Continuous, } \\
\text { Intermittent, } \\
\text { and } \\
\text { Transient }\end{array}$ & $\begin{array}{c}\text { F } \\
(\text { all } P= \\
.0001)\end{array}$ \\
\hline & $\mathbf{M} \pm \mathbf{S D}$ & $\mathrm{M} \pm \mathrm{SD}$ & $\mathrm{M} \pm \mathrm{SD}$ & $\mathrm{M} \pm \mathrm{SD}$ & $\mathrm{M} \pm \mathrm{SD}$ & $\mathrm{M} \pm \mathrm{SD}$ & $\mathrm{M} \pm \mathrm{SD}$ & $\mathbf{M} \pm \mathbf{S D}$ & \\
\hline Least & $1.7 \pm 2.0$ & $2.1 \pm 2.0$ & $1.3 \pm 1.7$ & $0.8 \pm 1.2$ & $2.3 \pm 2.3$ & $2.9 \pm 3.0$ & $1.1 \pm 1.5$ & $2.7 \pm 2.0$ & 13.3 \\
\hline Post-hoc & & $2,3,6$ & $1,4,7$ & $1,4,5,7$ & $2,3,6$ & 3 & $1,4,7$ & $2,3,6$ & \\
\hline Now & $2.9 \pm 2.5$ & $3.9 \pm 2.6$ & $2.2 \pm 2.1$ & $1.4 \pm 1.9$ & $3.5 \pm 2.4$ & $4.0 \pm 3.1$ & $2.0 \pm 2.1$ & $4.2 \pm 2.7$ & 20.8 \\
\hline Post-hoc & & $2,3,6$ & $1,4,5,7$ & $1,4,5,7$ & $2,3,6$ & 3 & $1,4,7$ & $2,3,6$ & \\
\hline Worst & $5.6 \pm 3.0$ & $6.2 \pm 2.7$ & $5.0 \pm 2.8$ & $2.8 \pm 2.8$ & $6.9 \pm 2.7$ & $6.3 \pm 2.9$ & $4.8 \pm 2.8$ & $6.9 \pm 2.3$ & 21.4 \\
\hline Post-hoc & & $2,3,6$ & $1,3,4,7$ & $\begin{array}{l}1,2,4,5 \\
\quad 6,7\end{array}$ & $2,3,6$ & 3 & $1,3,4,7$ & $2,3,6$ & \\
\hline
\end{tabular}

$\stackrel{a}{=}$ range of actual scores was $1-10$

Note: All Games-Howell pairwise comparisons presented in the post-hoc row were significant at $\mathrm{p}<0.05$ 
Table 4

Pain Quality by Pain Pattern Groups (N = 762)

\begin{tabular}{|c|c|c|c|c|c|c|c|c|c|}
\hline $\begin{array}{c}\text { Pain } \\
\text { Quality }\end{array}$ & Total & $\begin{array}{c}\text { Pattern } 1 \\
\text { Continuous } \\
\text { only }\end{array}$ & $\begin{array}{c}\text { Pattern } 2 \\
\text { Intermittent } \\
\text { only }\end{array}$ & $\begin{array}{l}\text { Pattern } 3 \\
\text { Transient } \\
\text { only }\end{array}$ & $\begin{array}{c}\text { Pattern } 4 \\
\text { Continuous } \\
\text { and } \\
\text { Intermittent }\end{array}$ & $\begin{array}{c}\text { Pattern 5 } \\
\text { Continuous } \\
\text { and } \\
\text { Transient }\end{array}$ & $\begin{array}{c}\text { Pattern } 6 \\
\text { Intermittent } \\
\text { and } \\
\text { Transient }\end{array}$ & $\begin{array}{c}\text { Pattern } 7 \\
\text { Continuous, } \\
\text { Intermittent, } \\
\text { and } \\
\text { Transient }\end{array}$ & $\begin{array}{c}\text { F } \\
(\text { all } P= \\
.0001)\end{array}$ \\
\hline & $\mathrm{M} \pm \mathrm{SD}$ & $\mathrm{M} \pm \mathrm{SD}$ & $\mathrm{M} \pm \mathrm{SD}$ & $\mathrm{M} \pm \mathrm{SD}$ & $\mathbf{M} \pm \mathbf{S D}$ & $\mathbf{M} \pm \mathbf{S D}$ & $\mathbf{M} \pm \mathrm{SD}$ & $\mathbf{M} \pm \mathrm{SD}$ & \\
\hline PRI-S & $11.2 \pm 7.9$ & $11.8 \pm 7.5$ & $8.7 \pm 7.2$ & $7.0 \pm 6.1$ & $13.3 \pm 6.8$ & $15.5 \pm 10.7$ & $10.2 \pm 7.6$ & $17.5 \pm 7.8$ & 17.0 \\
\hline Post-hoc & & $2,3,7$ & $1,4,7$ & $1,4,5,6,7$ & $2,3,6,7$ & 3 & $3,4,7$ & $1,2,3,4,6$ & \\
\hline PRI-A & $3.4 \pm 3.5$ & $3.8 \pm 3.7$ & $2.7 \pm 2.8$ & $2.7 \pm 2.1$ & $4.1 \pm 4.0$ & $5.3 \pm 4.1$ & $2.4 \pm 2.9$ & $5.2 \pm 4.8$ & 8.9 \\
\hline Post-hoc & & $2,3,6$ & $1,4,7$ & 1,7 & 2,6 & 6 & $1,4,5,7$ & $2,3,6$ & \\
\hline PRI-E & $1.9 \pm 1.7$ & $2.1 \pm 1.8$ & $1.5 \pm 1.6$ & $1.1 \pm 1.4$ & $2.3 \pm 1.7$ & $2.5 \pm 2.1$ & $1.5 \pm 1.5$ & $2.9 \pm 1.7$ & 10.6 \\
\hline Post-hoc & & $2,3,6$ & $1,4,7$ & $1,4,7$ & $2,3,6$ & - & $1,4,7$ & $2,3,6$ & \\
\hline PRI-M & $3.1 \pm 3.4$ & $3.4 \pm 3.5$ & $2.2 \pm 2.7$ & $1.5 \pm 2.6$ & $4.4 \pm 3.4$ & $4.4 \pm 3.7$ & $2.5 \pm 3.1$ & $6.0 \pm 4.0$ & 18.0 \\
\hline Post-hoc & & $2,3,7$ & $1,4,7$ & $1,4,5,7$ & $2,3,6$ & 3 & 4,7 & $1,2,3,6$ & \\
\hline PRI-T & $19.5 \pm 14.3$ & $24.1 \pm 14.0$ & $14.8 \pm 12.3$ & $12.3 \pm 10.6$ & $24.1 \pm 12.1$ & $27.7 \pm 18.7$ & $16.7 \pm 12.8$ & $31.5 \pm 16.3$ & 19.7 \\
\hline Post-hoc & & $2,3,6,7$ & $1,4,5,7$ & $1,4,5,7$ & $2,3,6,7$ & 2,3 & $1,4,7$ & $1,2,3,4,6$ & \\
\hline NWC & $7.6 \pm 4.6$ & $8.0 \pm 4.2$ & $5.9 \pm 4.4$ & $5.4 \pm 3.6$ & $9.1 \pm 3.7$ & $9.7 \pm 5.0$ & $7.0 \pm 4.5$ & $11.6 \pm 4.8$ & 19.0 \\
\hline Post-hoc & & $2,3,7$ & $1,4,5,7$ & $1,4,5,7$ & $2,3,6,7$ & 2,3 & 4,7 & $1,2,3,4,6$ & \\
\hline
\end{tabular}

Note: All Games-Howell pairwise comparisons presented in the post-hoc row were significant at $\mathrm{p}<0.05$

Key (actual range of scores): PRI-S = Pain Rating Index-Sensory (0-37); PRI-A = Pain Rating Index-Affective (0-14); PRI-E = Pain Rating IndexEvaluation (0-5); PRI-M = Pain Rating Index-Miscellaneous (0-17); PRI-T = Pain Rating Index-Total (0-78); NWC = Number of Words Chosen (1-20) 